\title{
Health-care Accessibility Assessment in Kazakhstan
}

\author{
Askhat Shaltynov ${ }^{1 *}$, Aizhan Raushanova ${ }^{2}$, Ulzhan Jamedinova $^{3}$, Aigerim Sepbossynova $^{4}$, Altay Myssayev $^{5}$, Ayan $_{\text {Myssayev }}^{6}$ \\ ${ }^{1}$ Department of Public Health, Semey Medical University, Semey, Kazakhstan; ${ }^{2}$ Department of Epidemiology, Biostatistics \\ and Evidence-Based Medicine, Al-Farabi Kazakh National University, Almaty, Kazakhstan; ${ }^{3}$ Department of Epidemiology and \\ Biostatistics University, Semey, Kazakhstan; ${ }^{4}$ Department of Family Medicine, Semey Medical University, Semey, Kazakhstan; \\ ${ }^{5}$ Department of Radioisotope Medicine, Nagasaki University Graduate School of Biomedical Sciences, Nagasaki, Japan; \\ ${ }^{6}$ Department of Innovations in Medical Education, Semey Medical University, Semey, Kazakhstan
}

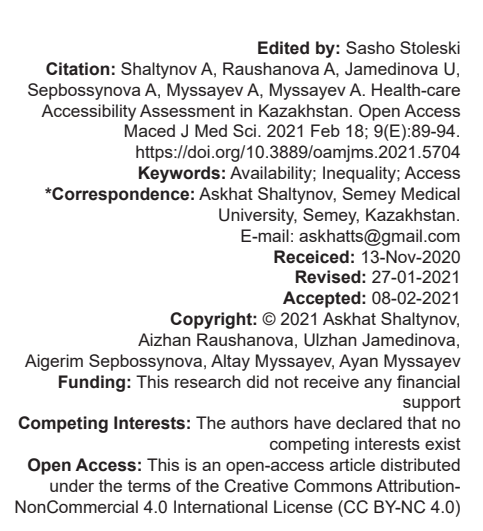

\begin{abstract}
BACKGROUND: Global health initiatives such as health for all and universal health coverage aim to improve access to health care. These goals require constant comprehensive monitoring to eliminate inequalities in the availability of health care.

AIM: The purpose of our study was to assess the physical availability of medical care in Kazakhstan.

METHODS: A descriptive study based on a Service Availability and Readiness Assessment (SARA) genera availability index calculation that used secondary data as a source of information.

RESULTS: The general availability index calculated for the regions of Kazakhstan ranged from $95 \%$ to $100 \%$. When considering individual indicators of the index, decrease trends of the volume of inpatient care were identified. Outpatient care had fluctuations with values better than benchmark after 2009. Stable upward trend illustrates positive picture of core health personnel.

CONCLUSION: According to the SARA availability index, it can be concluded that health care in Kazakhstan exceeds the threshold values and is available in all regions. Trends for individual indicators of the index should be studied in more detail, taking into account the influence of health policy and other factors.
\end{abstract}

\section{Introduction}

The World Health Organization (WHO) promoted the idea of health for all, which culminated in a conference on primary health care in Alma-Ata (today Almaty), Kazakhstan, in 1978. In 2013, the United Nations General Assembly adopted the Universal Health Coverage (UHC) concept [1]. Accessibility is a key focus of the above initiatives, as service capacity and access are one of the tracking areas of the UHC resolution [2].

Back in 1981, Penchansky and William Thomas identified accessibility as a pressing issue for health debate [3]. They grouped the concept of accessibility into five main domains: Affordability as a provider's cost versus a customer's willingness to pay for services; availability is the ability to have the necessary resources, such as personnel and technology, to meet a client's needs; and accessibility refers to geographic availability, which is defined by how easily a customer can physically reach a supplier's location; accommodation reflects the degree to which health-care services meet the client's wishes; acceptability reflects the degree to which the client is satisfied with the more consistent characteristics of the provider such as age, gender, social class, and ethnicity of the provider [4]. Accessibility of services relates to the physical presence of items needed to deliver services and encompasses health infrastructure, essential health personnel, and aspects of service utilization [5].

Data on assessing the availability of health care in the post-Soviet countries are not often published, which are overwhelmed or insufficient in scale [6], [7].

Data on assessing the availability of health care in Kazakhstan were studied for both inpatient and outpatient health care in rural areas, but they are also not comprehensive [8], [9].

One of the universal comprehensive tools for assessing accessibility is Service Availability and Readiness Assessment (SARA) tool developed by the WHO based on cooperation with U.S. Agency for International Development (USAID) [10], [11].

The aim of our study was a comprehensive assessment of the main indicators of the physical accessibility of healthcare in Kazakhstan using SARA availability index. 


\section{Methods}

\section{Study design}

We conducted a descriptive study, which based on secondary data from the official open source "Medinform" database that contains medical demographic indicators of the Kazakhstan by districts from 2000 to 2018 [12]. Information from this database were generated by 14 regions, two cities of republican significance and whole Kazakhstan. In addition, these indicators were divided for rural and urban settlements.

The assessment of availability based on the SARA tool developed by the WHO. We used Service Availability indicators $(n=6)$ facility density (number/10000 population), inpatient bed density (number/10000 population), health workforce density (number/10000 population), inpatient service utilization (according to SARA tool, it is number of hospital discharges, but in our study, we used number of hospitalizations/100 population/year), nurse to doctor ratio to compare rural, and urban population and outpatient outpatient visits per person per year and maternity beds $/ 1000$ pregnant women indicators to compare regions. Outpatient visits and maternity beds indicators data were available only for whole population without dividing to urban/rural population, hospitalization not hospital discharges indicator data was available in "Medinform" database. Facility density indicator was the sum of inpatient and outpatient facilities, workforce was included doctors, midwives, and nurses. Population data were taken from the statistical yearbooks issued by the agency of statistics, Kazakhstan [13].

\section{Statistical analysis}

Raw data of health facilities, health workforce, and number of hospitalization in "Medinform" database were presented in absolute numbers. We used standardization procedures according to SARA tool.

Average indicators were obtained separately for districts separately for cities to compare urban and rural indicators.

To compare, indicators between regions SARA service availability index were used. The service availability index is the un-weighted average of the three areas: Infrastructure, health workforce, and utilization:

a. $\quad(([a+b+c] / 3)+d+([e+f] / 2)) / 3$, and is $a$ percentage score, where health infrastructure

(a) facilities $/ 10,000 / 2 * 100(\max .100)$,

b. Inpatient beds/10,000/25*100 (max.100),

c. Maternity beds/1000 pregnant women/10*100 (max.100), health workforce

d. Core health workers/10,000/23*100 (max.100), service utilization

e. Outpatient visits/person/year/5*100 (max.100),

f. Hospital discharges/100/year/10*100 (max.100).
Max.100 means that if the tracer indicator score exceeds the benchmark, it will be scored as $100 \%$.

There were some not available indicators for rural districts. All missing values were replaced with median for the entire time for these districts.

All calculations were performed with $\mathrm{R}$ studio software (Rstudio, MA, USA) version 1.1.463 for Windows.

ArcGIS software (ESRI, CA, USA) 10.7 was used to creating interactive map of Kazakhstan.

\section{Ethical issues}

We did not use personal data for this reason, there was no need for information consent.

Ethical committee of Semey Medical University (Semey, Kazakhstan) approved our study, before it was started (protocol 2 dated 18 October 2019).

\section{Results}

Figure 1 displays data on the health-care facilities density/10,000 population for urban and rural areas from 2000 to 2018. As can be seen from the graph, the peak of facilities density was in 2008 with a further decline. In rural areas density indicator better, we bound it with that in our country, we have many primary district health-care facilities in rural areas.

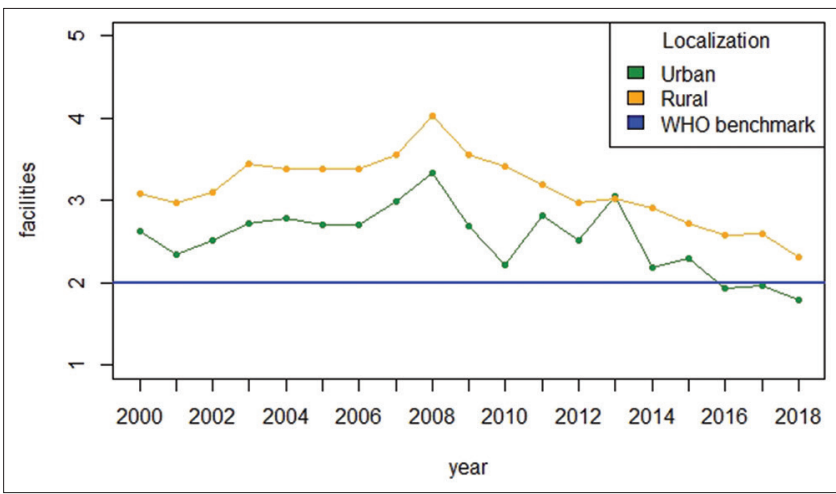

Figure 1: Health-care facilities/10,000 population during 2000-2018

Inpatient beds/10,000 population were presented better in urban areas with predominance of multidisciplinary hospitals (Figure 2). Inpatient beds density in rural areas has decline trend from 2010 with indicator $<25$ inpatient beds/10000 in 2018.

Doctors, nurses, and midwives rate/10,000 population have upward trend among urban and rural areas, but urban indicator was approximately $2 \frac{1}{2}$ times more for urban areas (Figure 3). However, even rural areas core health workers indicator more than 2 times more than international benchmark $(23 / 10000$ population). 


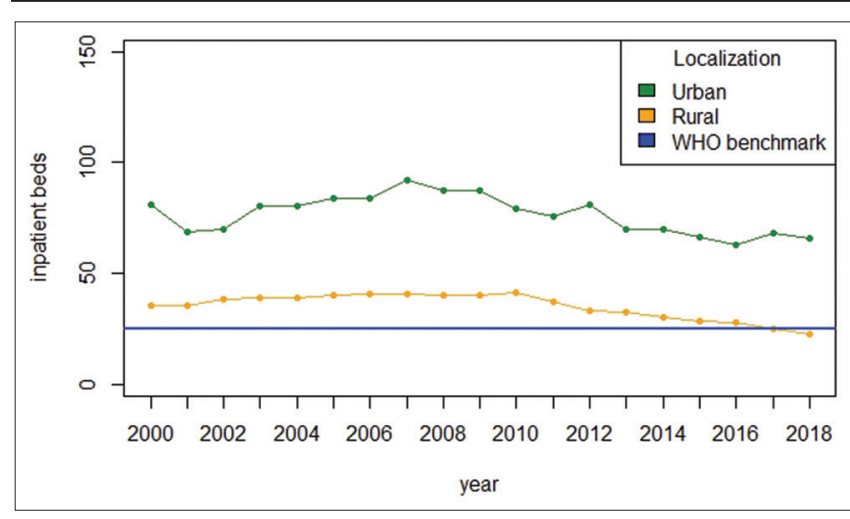

Figure 2: Inpatient beds/10,000 population during 2000-2018

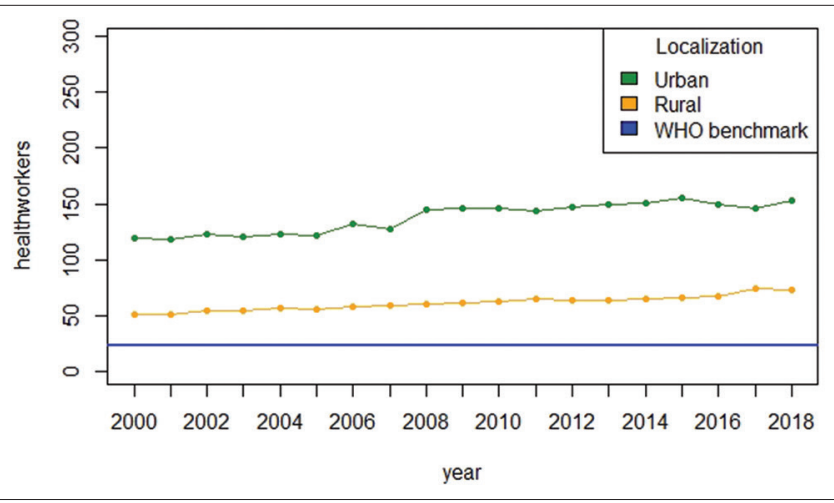

Figure 3: Core health workers/10,000 population during 2000-2018

International benchmark for number of hospital discharges/100 population is 10 . In our study, we found fluctuations of hospitalizations among rural population about international benchmark and fluctuations of hospitalization about 20/100 among urban population (Figure 4).

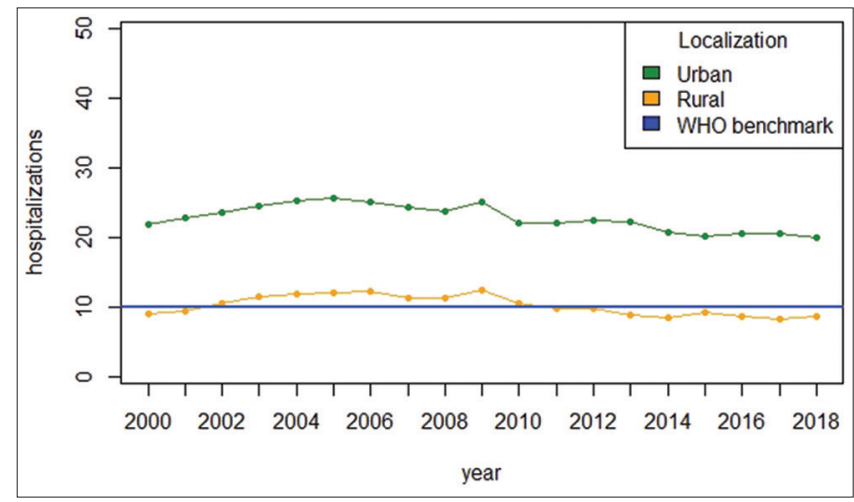

Figure 4: Number of hospitalizations/100 population during 2000-2018

The last two indicators were calculated only for whole country. Figure 5 demonstrates maternity beds/1000 pregnant women about twice less in 2018 than in 2000, but more than international benchmark about 2 times. Figure 6 reflects serious surges in outpatient care with rates higher than the benchmark after 2009. The peak of outpatient visits per person per year was in 2011 with 15 visits.

Availability index (Figure 7) as un-weighted average of six indicators in 2018 had the minimal percentage in Kostanay region (95\%). About 97\% availability index was calculated for Mangystau and South Kazakhstan regions, 98 \% for East Kazakhstan and Atyrau regions, and $99 \%$ for Pavlodar region and Nur-Sultan (former Astana) city. Other regions and Almaty city had the maximum availability index (100\%).

\section{Discussion}

To the best of our knowledge, this is the first descriptive study identifying availability index of healthcare in Kazakhstan and between Kazakhstan regions.

The idea of using methodology based on a part of SARA tool, we found at study protocol with aim of measuring readiness of primary health care for acute vascular events in rural low income settings [14].

Going to first area of un-weighted SARA availability index health-care facilities density in Kazakhstan, we define it 1.8 for urban areas and 2.3 for rural areas that about international benchmark for this indicator [10]. Bulletin of the WHO journal contains results of SARA implementation reports in Burkina Faso, Cambodia, Haiti, Sierra Leone, United Republic of Tanzania and Zambia [5]. The majority of these countries have $<2$ facilities $/ 10,000$ population, but in Cambodia, it is 3.6 and, in Sierra Leone, it is 2.1. In studies accessing availability of primary health care, this indicator is 4.6 primary health-care facilities in two districts of Mongolia and 6.7 in Mainland China $(15,16)$. We consider that the declining trend in the availability of facilities in our study is associated with an increase in the population from 14 millions in 2000 to 18 millions in 2018, while, since 2010, there has been a decrease in the number of hospitals [8].

A declining trend in facility density logically leads to a reduction in inpatient beds, we see lower rates in the rural areas, with an indicator of 22.5/10,000 population in 2018, in which we expect can be explained by the presence of multidisciplinary hospitals with a number of beds from 600 to 1000 only in urban areas [15], [16], [17]. This indicator calculated in other SARA studies were 14 in United Republic of Tanzania, 10 in China, and 21.6 in two districts of Mongolia.

We consider that fertility rate growth from 1.8 in 2000 to 2.84 in 2018 reflects sharply decrease of maternity beds from 39.5 to 20.7 for the same period [18].

The second area of un-weighted SARA availability index is presented only with health workforce capacity. In comparison with other SARA studies, Kazakhstan has rather high rates on this indicator [5]. This indicaor in primary health-care availability assesment were 61.2/10,000 in Mongolia and 26 in China [15], [16]. Very 


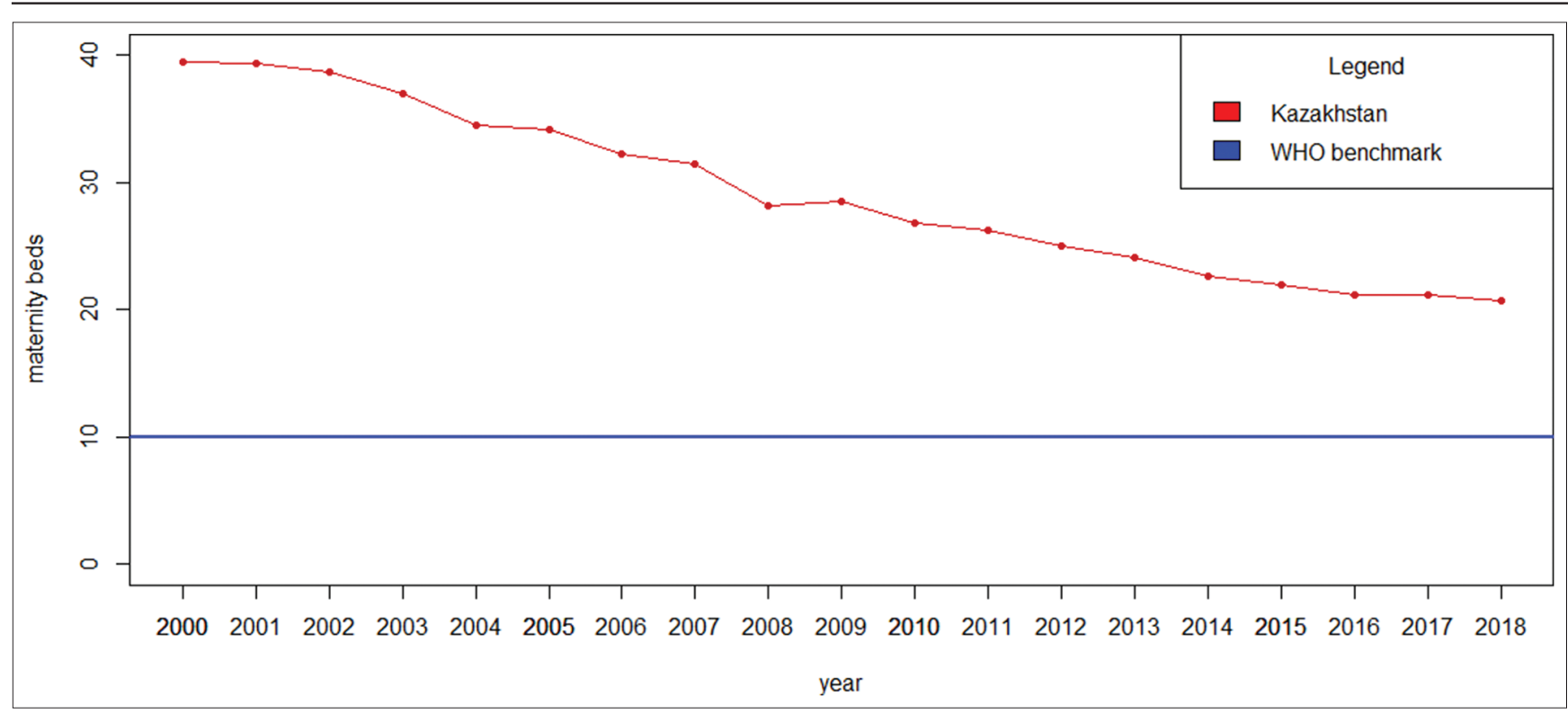

Figure 5: Maternity beds/1000 pregnant women

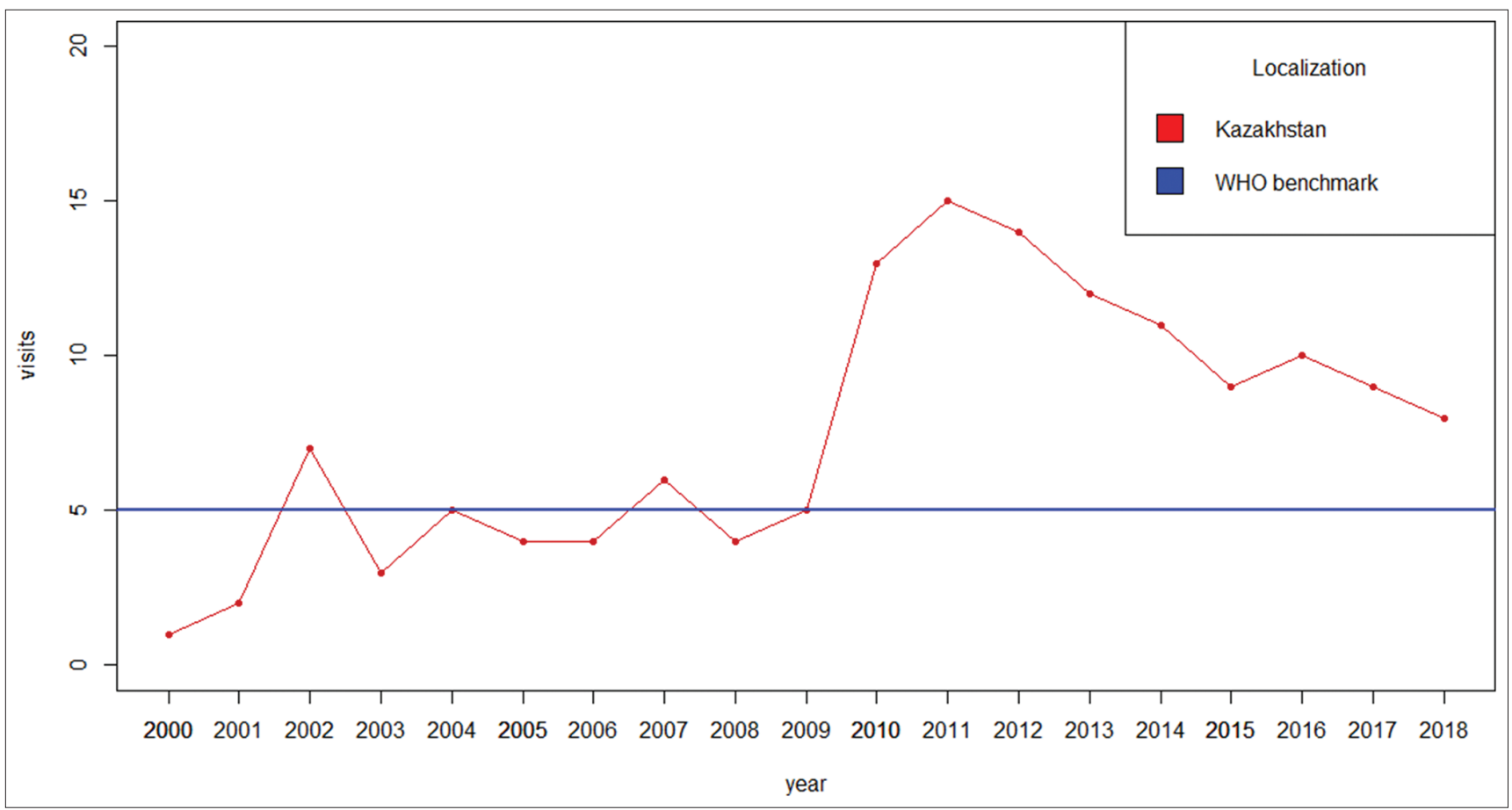

Figure 6: Outpatient visits per person per year

interesting data were received by researchers in Canada, where 11.7 and 7.2/1000 population nurses in average, respectively, for urban and rural areas and only 2.6 and 1.1 doctors/1000 population for cities and rural areas, respectively [19]. Based on these data, we can conclude that the nurse to doctor ratio is important: In Canada, it is 4.7 , in Mongolia, where the accessibility index was studied, this indicator is 1.4 to 1 . We did not present the calculation of this indicator for the sake of the methodology for calculating the accessibility index. For urban and rural areas of Kazakhstan, it is 1.9 and 3.4, respectively.

Calculated utilization measured with outpatient visits was almost similar with OECD33 consultation with doctor indicator in 2017 (6.8 visits/capita/year). Hospital discharge rates in OECD36 (154/1000 population) significantly higher than the hospital admissions calculated in our study [20].

If we carefully consider the trends for each indicator of the comrehensive availbality assessment, then it is possible to change the change in the curves from 2009 to 2010, which corresponds to the period of the health care reform "Salamatty Kazakhstan" aimed at optimizing inpatient care and strengthening the role of outpatient care. In general, the trends presented for urban and rural areas which were in line with the conclusions of the experts of the European 


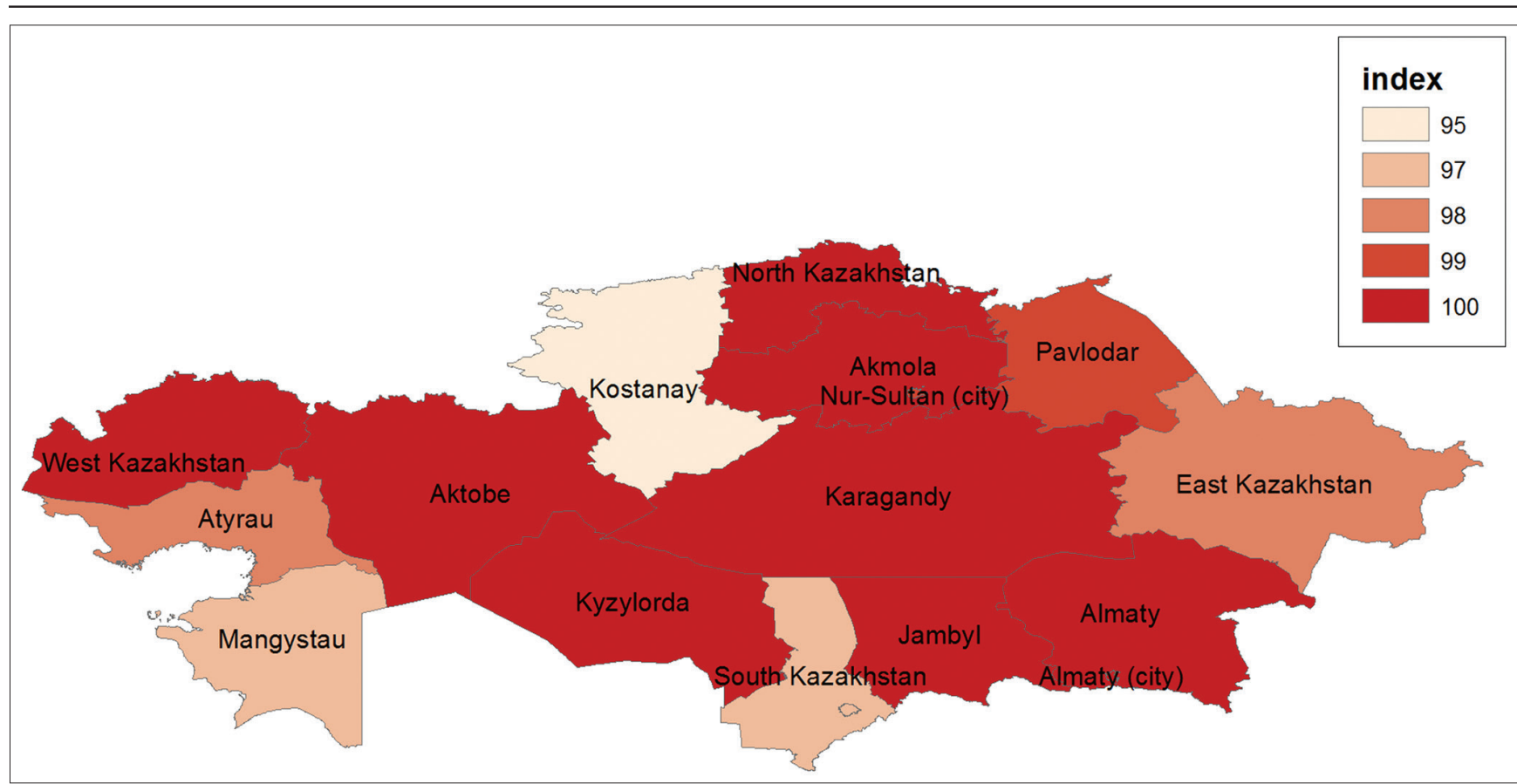

Figure 7: Service availability index in 2018

Observatory on Health Systems and Policies who noted the "bloated" inpatient care received since the Soviet Union, inequality in the availability of health care in rural areas [17].

Finally, discuss about availability index, it was at maximim level almost in whole regions of Kazakhstan which may require other research methods that may appear in a new tool developing by the WHO, World Bank, and USAID [21].

\section{Limitations}

We use only general service availability index from SARA tool, for complex availbaility assesment, it will be better to calculate readiness index too. The main drawback of our study, it is secondary data, although it is allowed by SARA manual to use master facility list to calculate the availability index, it is better to conduct a survey.

\section{Conclusion}

It can be noted that our study revealed some trends in indicators of access to medical care that should be studied in the future, taking into account additional factors. In general, since 2009-2010 in Kazakhstan, there has been a decrease in indicators related to inpatient care; however, they still remain higher than the WHO benchmark. The SARA general availability indicator calculated for the regions is at least $95 \%$, which indicates excellent physical accessibility; however, we identified an imbalance between rural urban areas.

\section{References}

1. Pandey KR. From Health for All to Universal Health Coverage: Alma Ata is Still Relevant. Globalization and Health; 2018. https://doi.org/10.1186/s12992-018-0381-6

2. Bloom DE, Khoury A, Subbaraman R. The promise and peril of universal health care. Science. 2018;361(6404):eaat9644. https://doi.org/10.1126/science.aat9644

PMid:30139847

3. PenchanskyR, Thomas JW. The concept of access: Definition and relationship to consumer satisfaction. Med Care. 1981;19(2):12740. https://doi.org/10.1097/00005650-198102000-00001 PMid:7206846

4. McLaughlin CG, Wyszewianski L. Access to care: Remembering old lessons. Health Serv Res. 2002;37(6):1441-3. https://doi. org/10.1111/1475-6773.12171

PMid: 12546280

5. O'Neill K, Takane M, Sheffel A, Abou-Zahr C, Boerma T. Monitoring service delivery for universal health coverage: The service availability and readiness assessment. Bull World Health Organ. 2013;91(12):923-31. https://doi.org/10.2471/ blt.12.116798

PMid:24347731

6. Balabanova D, McKee M, Pomerleau J, Rose R, Haerpfer C Health service utilization in the former Soviet Union: Evidence from eight countries. Health Serv Res. 2004;39(6 Pt 2):1927-50. https://doi.org/10.1111/j.1475-6773.2004.00326.x PMid:15544638

7. Antonova N. Access to healthcare in Russia: A pilot study in Ekaterinburg. Cent Eur J Public Health. 2016;24(2):152-5. https://doi.org/10.21101/cejph.a3942 


\section{PMid:27434248}

8. Kumar AB, Izekenova A, Abikulova A. Inpatient care in Kazakhstan: A comparative analysis. J Res Med Sci. 2013;18(7):549-53.

\section{PMid:24516484}

9. Sagyndykova Z, Turdaliyeva B, Altynbekova U, Aimbetova G, Meirmanov S. Analysis of availability to health care for the population of Kazakhstan at the Primary health care. Eur $\mathrm{J}$ Public Health. 2016;26:120. https://doi.org/10.1093/eurpub/ ckw167.031

10. World Health Organization. Service availability and readiness assessment (SARA): An annual monitoring system for service delivery reference manual, version 2.2. Health Stat Inf Syst. 2015;2015:178.

11. Ali M, Farron M, Dilip TR, Folz R. Assessment of family planning service availability and readiness in 10 African countries. Glob Heal Sci Pract. 2018;6(3):473-83. https://doi.org/10.9745/ ghsp-d-18-00041

PMid:30213877

12. Medinform. Available from: http://www.medinfo.kz/\#/stats. [Last accessed on $2020 \mathrm{Jul} 20$ ].

13. Statistics Committee. Available from: https://www.stat.gov.kz. [Last accessed on $2020 \mathrm{Jul} 20]$.

14. Ahmed S, Chowdhury MAH, Khan MA, Huq NL, Naheed A. Access to primary health care for acute vascular events in rural low income settings: A mixed methods study. BMC Health Serv Res. 2017;17(1):47. https://doi.org/10.1186/s12913-017-1987-8
PMid:28100208

15. Jigjidsuren A, Byambaa T, Altangerel E, Batbaatar S, Saw YM, Kariya $\mathrm{T}$, et al. Free and universal access to primary healthcare in Mongolia: The service availability and readiness assessment. BMC Health Serv Res. 2019;19(1):129. https://doi.org/10.1186/ s12913-019-3932-5

PMid:30786897

16. Zhang $Y$, Wang $Q$, Jiang $T$, Wang J. Equity and efficiency of primary health care resource allocation in mainland China. Int J Equity Health. 2018;17(1):140. https://doi.org/10.1186/ s12939-018-0851-8

PMid:30208890

17. Katsaga A, Kulzhanov M, Karanikolos M, Rechel B. Kazakhkstan health system review. Health Syst Transit. 2012;14(4):1-154. PMid:22894852

18. Fertility Rate, Total (Births per Woman)-Kazakhstan|Data Available from: https://www.data.worldbank.org/indicator/ SP.DYN.TFRT.IN?locations=KZ. [Last accessed on $2020 \mathrm{Jul} 20$ ].

19. Ariste R. Availability of health workforce in urban and rural areas in relation to Canadian seniors. Int $\mathrm{J}$ Health Plann Manage. 2019;34(2):510-20. https://doi.org/10.1002/hpm.2712

20. Organisation for Economic Co-operation and Development. OECD Health at a Glance 2019. OECD Library; 2019.

21. The Harmonized Health Facility Assessment (HHFA). Available from: https://www.who.int/hospitals/assessment-tools-andchecklists/18155_A4-Flyer_rev.pdf?ua=1. [Last accessed on 2020 Jul 20]. 